Article

\title{
Adoption of Automatic Warehousing Systems in Logistics Firms: A Technology-Organization-Environment Framework
}

\author{
Jingjing Hao ${ }^{1}$, Haoming Shi ${ }^{2,3}$, Victor Shi ${ }^{4}$ and Chenchen Yang ${ }^{1, *}$ \\ 1 School of Economics, Hefei University of Technology, Hefei 230009, China; jhao@hfut.edu.cn \\ 2 Department of Economics and Trade, Guangzhou College of Technology and Business, Guangzhou 510850, \\ China; howardshi2@gmail.com \\ 3 Faculty of Business, City University of Macau, Avenida Padre Tomás Pereira Taipa, Macau 999078, China \\ 4 Lazaridis School of Business and Economics, Wilfrid Laurier University, Waterloo, ON N2L 3C5, Canada; \\ cshi@wlu.ca \\ * Correspondence: yangcc@hfut.edu.cn; Tel.: +86-551-63831807
}

Received: 30 April 2020; Accepted: 23 June 2020; Published: 25 June 2020

\begin{abstract}
The adoption of automatic warehousing systems, a type of green technology, has been an emerging trend in the logistics industry. In this study, we develop a conceptual model using a technology-organization-environment framework to investigate the factors which influence logistics firms to adopt green technology. Our model proposes that the adoption of green technology is influenced by perceived advantage, cost, technological turbulence, business partner influence, firm size, firm scope and operational performance. The objective of this study is to identify the conditions, as well as the contributing factors, for the adoption of automatic warehousing systems in logistics firms. Data were collected from 98 firms in China, and structural equation modeling with partial least squares is adopted to analyze the data. The results suggest that high perceived relative advantage, firm size, cost, firm scope, operation performance, technological turbulence and influence of business partners are important factors affecting IT adoption in small businesses. Therefore, decision support should be provided for enterprises from the three aspects of technology, organization and environment to improve the adoption of automatic warehousing systems.
\end{abstract}

Keywords: automatic warehousing systems; green technology; TOE framework; adoption

\section{Introduction}

Automatic warehousing systems (AWS) are commonly adopted in the manufacturing, logistics, and retail industries. In this study, we examine AWS as a type of green technology, which is crucial for firms to survive and grow in the sustainable environment by creating sustainability value [1]. The scarcity of land resources in recent years has given rise to the demand for continuous development of AWS using information and automation. This system is closely linked to enterprise material flow and widely utilized in business, city traffic management, and other areas. AWS generates savings in cost and energy and also improves efficiency and business intelligence. Ultimately, AWS can improve the efficiency of supply chains. Logistics is a common word nowadays, since it has an important role in supply chains and also in the competition of firms [2].

The logistics industry is positively related to economic development. In recent years, the e-commerce transaction scale has increased from 5416 million yuan (USD 763.34 million) in 2011 to 9534 million yuan (USD 1343.74 million) in 2018; e-commerce is rapidly becoming the world's largest market. E-commerce in the world, especially the logistics industry, is currently in rapid development. E-commerce logistics techniques and equipment will develop towards automation which gives high 
efficiency for human benefit. For example, in the express industry, the daily receipt and delivery of goods are extremely frequent; thus, speed and accuracy are the basic requirements in a warehouse system application. However, in real life, not all warehouses have quick access to goods, so optimizing the warehouse ground area utilization rate is crucial. The existing warehouse resources face major challenges in increasing their utilization rate, improving scale efficiency, and reducing logistics costs. In most cases, AWS is used to ameliorate such problems. Although information technology (IT) is widely applied in the logistics industry, AWS technology applications are relatively new. Internet of Things and smart factories have a positive role in promoting information technology implementation, which contributes to sustainable business performance [3]. Given the popularization of the Internet and the development of smart devices and e-commerce platforms, customers are making fewer trips to offline stores, which are restricted by physical opening and closing times.

At present, online customer service staff come to work each day and find multiple pending orders that require delivering the ordered goods to customers as soon as possible. Sustainable green technology is an important contributor to the creation of a sustainable society through the simultaneous promotion of environmental protection and economic development [4]. Consumers consider green product attributes somewhat but are also affected by other attributes, such as cognitive values, individual environmental literacy, price, and brand equity [5]. Finished products are quickly shipped from the seller warehouses to the logistics warehouse, and then from the logistics warehouse to storage and distribution facilities. The efficiency of a warehouse has an extremely important impact on storage and delivery. Competing in the market requires continuous improvements in the design and operation of production-distribution networks, which in turn require high performance from warehouses. Therefore, AWS are being used by companies to save time and costs. The emergence of AWS is considered a symbol of the rise of high-tech firms for material movement.

Warehousing is an important part of the supply chain and plays a key role in facilitating production efficiency [6]. The logistics industry has rapidly increased at an annual rate of $9.65 \%$ from 1980 to 2010 [7], and currently, the logistics costs in the United States are approximately $8 \%$ of GDP, while the logistics costs in Japan are approximately $11 \%$ of GDP. Driven by rapid economic growth, satisfying the demand for logistics services is difficult, and firms must manage all kinds of customer demands. Although the mechanism or system for storing and managing requirements differs for each firm, saving space is always a positive change. Warehouse utilization is intended to save space, such that $50 \%$ more products can be packed onto each shelf. However, this concept of a concentrated warehouse is gradually moving toward the growth strategy to a sustainable model in response to the limits-to-growth dilemma [8]. The deterioration of the natural environment has attracted research attention toward green technology, and the sustainable development efforts of an increasing number of countries focus on energy conservation and emission reduction. Strategic transformation focuses on developing a sustainable model that utilizes green technology, which can both facilitate economic efficiency and reduce pollution.

As customers are more concerned with the care of the environment, companies are required to be more aware of their actions [9]. Firms must invest in green technology and better energy efficiency to solve environmental problems. Since AWS reduce costs and improve performance, these types of systems comprise a new and globally expanding industrial field that can be considered a green technology with high quality, high efficiency, and less pollution. Firms generally adopt new technologies, but some of these new technologies are not adopted due to features that do not fit the environment and overall firm structure. This study analyzes the factors that affect the adoption of new green technology, namely, AWS of logistics firms, which require manual storage and retrieval of a unit load using a forklift or crane. Therefore, this study examines the factors that affect the AWS adoption among firms.

Based on data collected from 98 Chinese logistics firms and a technology-organization-environment framework, this paper investigates the contributing factors for the adoption of automatic warehousing systems in logistics firms. Management insights and implications are provided for managers of logistics firms as well as manufacturers of automatic warehousing systems.

The rest of this study is organized as follows. Section 2 discusses the literature on automatic warehousing systems and technology adoption. Section 3 describes the research model and hypotheses, 
after which Section 4 presents the research methodology. The data analysis appears in Section 5. Finally, Section 6 presents conclusions and discussion of the results.

\section{Literature Review}

\subsection{Automatic Warehousing Systems}

In recent decades, studies have focused on AWS with the aim of improving firm performance. The literature reviewed regarding design emphasizes the importance of improving the performance of 2D and 3D AWS.

Randhawa and Shroff (1995) showed that having the Input/Output $(\mathrm{I} / \mathrm{O})$ point located at the bottom and middle of the storage aisle results in higher throughput than having it at the end of the aisle [10]. Vasili et al. (2012) investigated the performance of the split-platform automated storage and retrieval system, which can be enhanced for a range of rack configurations by introducing two I/O points per aisle [11]. Ashayeri et al. (2003) determined the advantages of the class-based storage assignments in a 2D automated storage and retrieval system with two I/O points at floor level on opposite ends of each aisle [12]. The above studies show that a suitable design of the I/O point in different types of 2D automated storage and retrieval systems contributes to performance improvement. According to the automated storage and retrieval system (AS/RS) literature, AWS offers several benefits that lead to high efficiency and improvement in production $[13,14]$. As one of these advanced technologies, shuttle-based storage and retrieval systems (SBS/RS) are developed to process more loads and achieve higher speed than mini-load crane-based automated storage and retrieval systems [15].

Extending the work of Bozer and White (1984) [16], de Koster et al. (2008) designed an intelligent 3D automated storage and retrieval system [17] to analyze its performance and optimal dimension. Their proposed system consists of a crane or S/R machine and a series of conveyors. Travel time is calculated, and the optimal dimensions for minimizing travel time are investigated. Two kinds of conveyor belts are investigated, one with gravity conveyors and the other with powered conveyors. Three dimensions were considered, namely, the horizontal, vertical, and depth dimensions. The 3D automated storage and retrieval systems are comprised of a rack, a crane (Storage/Retrieval machine), an I/O point, and a series of conveyor belts. Along the storage aisles, the crane is used to move the goods in the horizontal and vertical directions while the conveyor is used to place and move the goods with depth movements. Ekren et al. (2015) found the best rack design for SBS/RS under a class-based storage policy. SBS/RS is a new technology developed for high transaction environments where the mini-load AS/RS crane may be unable to keep pace with the transaction rate needed over a given number of storage locations [18].

\subsection{Technology Adoption}

Green technology is closely related to new technology adoption, which is commonly examined using the technology-organization-environment (TOE) model. TOE contexts are significant influencers of new technology adoption [19]. Xia et al. (2019) promoted the systematic analysis pattern of green technology adoption and transformation in business [20]. Zhu and Kranemer (2005) built an integrated model based on stage and diffusion of technology. The assimilation of technology, organization, and environmental concerns are influenced by the technical preparation state, technical integration, firm size, firm scope, management barrier, competition strength, and management environment [21]. Sinkovics and Kim (2014) proposed a new theory by integrating the TOE model with the resource-based view (RBV) and contingency theories; their work verifies the causes and consequences of trans-boundary electronic collaboration and expanded the connotations of TOE model [22]. Based on the TOE framework, Aboelmaged (2014) determined the factors that affect electronic maintenance technology in the manufacturing industry, including basic technical facilities, prospective earnings, and challenges in electronic maintenance [23]. Teo et al. (2009) collected data from firms in Singapore through a questionnaire to determine the factors that affect the adoption of electronic procurement technology. The TOE framework was adopted and revealed various influencing factors, such as firm size, support of senior executives, indirect benefit perception, and business factors. These factors showed positive and remarkable influences on enterprise 
adoption of electronic procurement [24]. Frambach and Schillewaert (2002) proposed a unified framework and discussed the main factors that influence organizational acceptance. Organizational influence on enterprise adoption of new technology has been highly emphasized in marketing and management for the past 20 years [25]. Thong and Yap (1995) studied the influences of CEO and organization characteristics in the IT adoption of small firms [26].

Yoon et al. (2020) presented relative advantages, complexity, and compatibility of technology, CEO innovativeness, and IT knowledge, as well as various factors for technology adoption of open systems in agriculture based on the TOE framework [27]. A technology acceptance strategy was proposed from two perspectives, namely, organization and individual receivers, and the factors affecting the adoption of AWS systems of small and medium firms were analyzed. Chatterjee and Kar (2020) found that the adoption of social media improves SME performance [28]. Cruz-Jesus et al. (2019) developed a conceptual model using the TOE framework to assess the antecedents of CRM adoption stages using partial least squares structural equation modeling with the data obtained from 277 firms [29]. Liu (2020) explored the adoption of learning technologies by academics within higher education to develop a framework that integrates current scholarly knowledge and informs practice and future research [30].

Although the literature about automatic warehouse systems and technology adoption continues to grow, few investigations have looked at the effects of automatic warehouse system adoption, and it is unclear whether the growing influence of the logistics industry can play a role in slowing down the growth of production. To fill this gap, this paper aims to examine the effect of adopting AWS in the logistics industry.

\section{Research Model and Hypotheses}

\subsection{Research Model}

Figure 1 illustrates the proposed model, which is based on the relations among variables such as technical perspective (including cost and perceived relative advantage of AWS), organizational perspective (including firm size, firm scope, and operation performance), and environmental perspective (including technological turbulence and business partners) in the TOE (technology-organizationenvironment) framework.

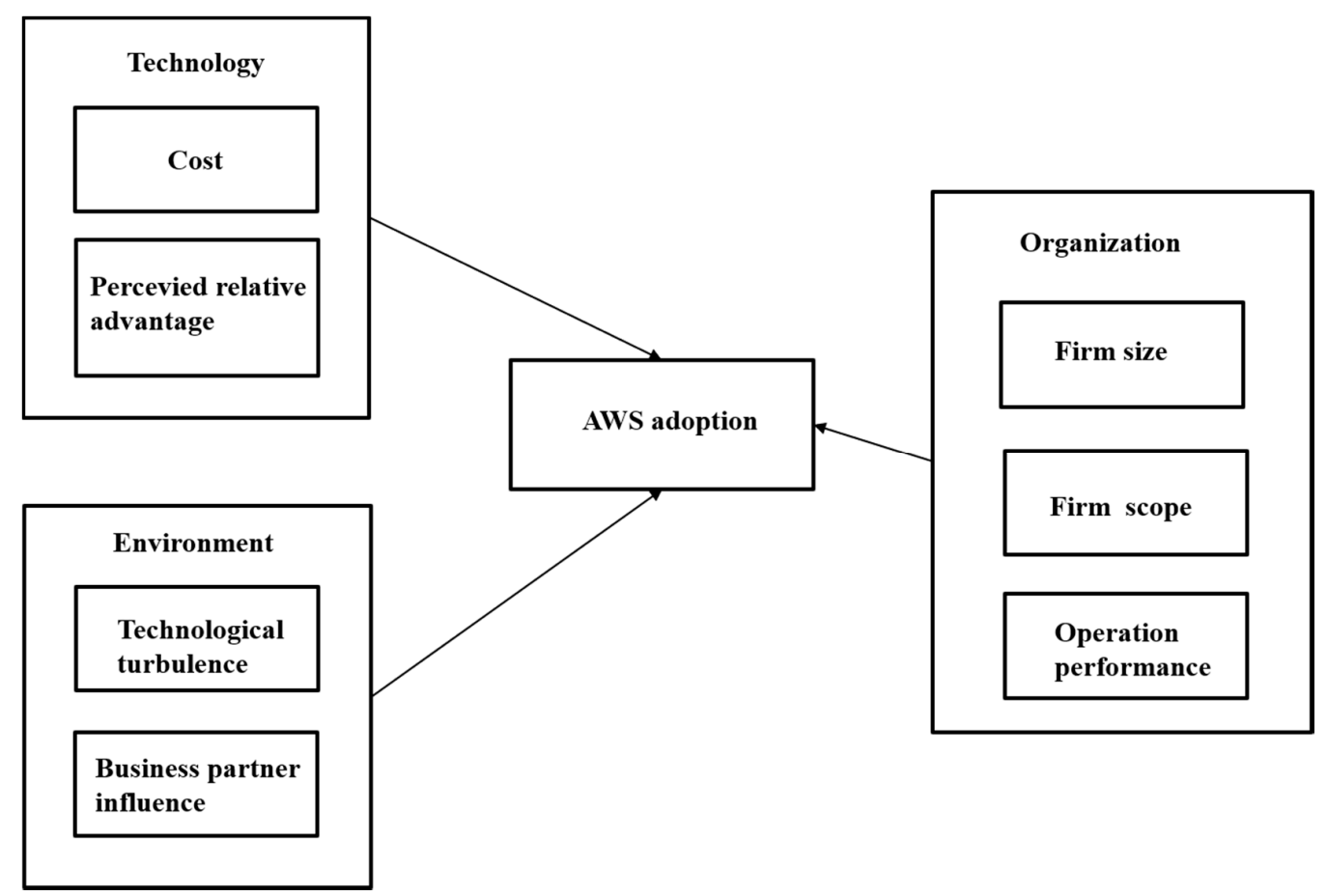

Figure 1. Research Model. 


\subsection{Technology Context}

An enterprise may analyze the related advantages of AWS from several aspects, such as employees, output, resources, and work efficiency. An enterprise will increase its output using AWS. Premkumar and Roberts (1999) obtained empirical data of 78 rural firms through interviews and used the TOE model to study the factors that affect the acceptance of new IT. Their proposed research model included ten independent variables in the three categories of innovation, organization, and environment. In accepting new communications technology, a larger advantage results in easier adoption among firms [31]. Ingrid and Patrick (2015) indicated that the effects of perceived relative advantage, compatibility, and lack of complexity, along with the influence of subjective media norms on usage intention, are all partially mediated by the emotions toward electric vehicles (EVs) [32]. Park and Lim (2018) showed that the perceived cost of EVs is negatively related to its usage intention [33]. Firms aim to make profits, and thus reducing costs is critical. The high prices of AWS discourage enterprises not only from considering the benefit of green technology, but firms also consider the ability of their technicians to use such systems. Logistics companies and warehouse operators consider costs based on their customers worldwide before moving the sorting process of goods away from consuming countries. Logistics firms provide services such as transportation, warehousing, cross-docking, inventory management, packaging, and freight forwarding. Logistics comprises warehousing, transportation, loading and unloading, handling, carrying, packaging, processing, distribution, and logistics information.

If technicians cannot use AWS technology, then enterprises also consider the training cost and the necessity of introducing AWS. Training and employing warehouse talents requires financial expenditure. The durability of the AWS, cost for maintenance, and necessity for software updates can influence the adoption of AWS. Accordingly, we propose the following hypotheses:

Hypothesis 1 (H1). High perceived relative advantage of AWS leads to a high possibility for a logistics firm to adopt AWS.

Hypothesis 2 (H2). High costs of AWS lead to a low possibility of firm adoption.

\subsection{Organization Context}

Whether large firms can adopt burgeoning technology more easily than small firms is a common question regarding AWS adoption. Similarly, the quantity of patents that large firms obtain every year is expected to be higher than what small and medium firms can achieve. However, in reality, the technology adopted by small and medium firms is more advanced than that of large enterprises. Moreover, the annual quantity of national patent applications of small firms is higher than that of large firms. The competitive pressure of small firms is heavier than that experienced by large firms in the current market. Large firms have abundant financial resources and, further, possess the ability to use new technologies. Thong and Yap (1995) reported that larger firm sizes lead to easier IT acceptance [26]. Aboelmaged (2014) stated that the scale of an organization and enterprise ownership influence the use of electronic maintenance technology [23]. Premkumar and Roberts (1999) assumed that an enterprise might already possess considerable resources for electronic maintenance technology. Thus, IT utilization is easier for larger firms due to their capacity to invest in and introduce new technology [31].

Business sustainability enables the integration of financial economic sustainability performance and non-financial environmental, social, ethical, and governance sustainability performance dimensions into the corporate culture, supply chain management and business models in creating shared value for all stakeholders [34]. Any firm's development depends on customer accumulation. An enterprise can maintain regular customers by satisfying their requirements in order to attain a good reputation. AWS may have quickly destroyed labor jobs, but it has also recently created jobs in unprecedented numbers. The new green technology provides a flexible business process model that allows firms to respond quickly to new customer requirements, new business opportunities, and competitive threats. If products are not updated innovatively, customers will likely purchase other brands. Therefore, firms 
must introduce new products to satisfy the customer's fondness for novelty. In a constantly changing market, every enterprise maintains its market share by studying new products or upgrading their original offerings. However, developing new products is difficult and often requires new technology. The trust between the customer and enterprise mainly stems from the business activities of an enterprise. Firms must ensure timely delivery or keep promises to complete transactions. When an enterprise fails to complete the time or fulfill customer requirements, customers look for a new partner. Firms must also maintain a good reputation. If a firm completes customer orders and performs timely delivery with high quality, then customers continue to support that firm. Manufacturing firms that produce the same products or offer similar services expend much effort to maintain their market share in the face of fierce competition. However, a firm can keep a foothold in the market only by providing high-level services to customers. Accordingly, we propose the following hypotheses:

Hypothesis 3 (H3). Firm size has a positive effect on AWS adoption.

Hypothesis 4 (H4). Firm scope has a positive effect on AWS adoption.

Hypothesis 5 (H5). Operation performance has a positive effect on AWS adoption.

\subsection{Environment Context}

Green technology facilitates better productivity and lower labor costs. However, green technology remains in its infancy, and the industry is constantly changing. Given these factors, firms struggle to adopt new technology. A firm that adopts new technology expects improvement and beneficial growth. Given a fierce market competition, in which customer demands constantly change, the traditional competitive strategy is considered unfit for the subsistence and development of enterprises. The ability to meet customer needs is one of the core competences of modern logistics firms, so the process of meeting customer demand is the pursuit of firms. Customer value determines customer satisfaction and fidelity; customer satisfaction is closely related to repurchase intention. Logistics firms consider changes in the industry when adopting new technology. Enterprises emphasize partnership with other businesses, which results in a positive and remarkable influence on the adoption of new technologies [24]. Firms also consider the benefits that AWS brings to their business partners. A downstream firm that cooperates with the production firm shortens the time needed for receiving goods and reduces the risk of both the deterioration of goods during storage and damage during collection. Customers eliminate firms if they are not satisfied with the service due to outdated technology. Customers choose to cooperate with technologically advanced firms because, after all, they aim to gain benefits. Accordingly, we propose the following hypotheses:

Hypothesis 6 (H6). Technological turbulence has a positive effect on AWS adoption.

Hypothesis 7 (H7). The influence of business partners has a positive effect on AWS adoption.

\section{Research Methodology}

\subsection{Measurement}

In order to identify and confirm all major concerns of green technology adoption by logistics firms, a survey was designed and sent to the managers of warehouse firms. To guarantee the accuracy of variable measurements, a questionnaire was adopted as the item of measurement used to prove feature reliability and validity. The questionnaire in this study was adapted from mature measurement scales using variables common in previous studies. The variables were measured according to the specific research background. Items were scored using a five-point Likert scale, with "extremely disagree," "disagree very much," "neutral," "agree," and "agree very much" as choices 1-5, respectively. The variable indices of the survey questionnaire include perceived relative advantage, cost, firm size, firm scope, operation performance, business partner influence, AWS adoption, and technological turbulence. 
The questionnaire survey method was adopted to collect firsthand survey data. The proposed theoretical model was verified using the data collected through analysis with statistical software. The specific research objects were then investigated, and finally, the proposed hypothetical model was verified through analysis of the collected data. The advantages of this survey approach include high standards and fast recovery. Moreover, several research objects can be investigated within a short time, and firsthand data can be obtained. Analysis can then be conducted using statistical software. One shortcoming of the questionnaire method is that respondents might answer the questions incorrectly due to carelessness or misunderstanding of the questions. These circumstances are inevitable.

First, the questionnaire was developed. The scales of the questionnaire were designed as a series of measurement problems in a survey approach. Preliminary versions of the questionnaires were tested, and items were revised or deleted when found to contain problems. After completing the primary questionnaire design, the questionnaire was revised after consulting an expert who was proficient in warehouse systems. The survey scope of the questionnaire involves firms in China, so the questionnaire had to be translated into Chinese. During translation, the research group members inspected the questionnaires to guarantee the accuracy of each variable item after repeated comparison and translation. A pre-survey was conducted, and the questionnaires were further revised and improved.

Second, after the questionnaire was finalized, the test subjects (respondents) were selected to complete the questionnaire. The questionnaires were sent to the respondents for data collection. Third, the behavior and attitude of respondents were measured through data analysis. To do so, the respondents were informed of the purpose of this research and were given instructions about how to answer the questions. The respondents were encouraged to follow three principles when answering the questionnaire, namely, concentration, conciseness, and simplicity. Fourth, the answers of the respondents were sorted after data collection.

\subsection{Data Collection}

This section discusses the factors that influence the enterprise adoption of AWS. Middle senior managers with related experience in warehouse management were selected as respondents due to their capacity to decide and advise on the introduction of new technology into an organization. The questionnaires were sent out in two ways. First, the questionnaires were sent to firms in the cities of Hefei and Shanghai through an acquaintance of the researcher. Second, the questionnaires were sent via social media platforms using links to a professional website. Before sending the questionnaires, the researcher instructed the acquaintance to explain the survey purpose and the time needed to answer the questionnaire. The respondents were allowed to indicate an email address if they requested to see the final research results, which were provided after this study had concluded. Upon survey completion, the investigator personally inspected the returned questionnaires. If their completed questionnaire had sufficient quality, the researcher later sent a scanned copy of the final results to the respondent by email. For questionnaires filled in through the website, the researcher personally downloaded and analyzed the questionnaire data.

Our questionnaire screening followed these standards. First, the answers must be complete. Incomplete questionnaires were excluded from this study. Second, the industry selection section in personal information was checked. Questionnaires from respondents in industries that are not related to warehousing were also excluded. Third, extreme answers to questions with multiple options were checked and excluded, such as responses given by selecting the same figure. A total of 120 questionnaires were collected, and 22 were ineffective and incomplete. Thus, we obtained 98 effective questionnaires, which is equivalent to an $81.7 \%$ response rate. It is noteworthy that the enterprises investigated in this paper have the common characteristics of the industry, including a development level in line with international standards. Furthermore, China's logistics enterprises are developing at a very fast speed, and their management is also in line with international standards. Consequently, managerial insights obtained based on this data can also provide suggestions for enterprises in other countries. The item used for measurement are provided in Appendix A. 


\section{Data Analysis}

Among the respondents, $70.4 \%$ are male, and $29.6 \%$ are female. Respondents aged below 30 account for $52 \%$, those aged 30-39 account for 38.8\%, and those aged $40-49$ account for $9.2 \%$. The characteristics of the sample are shown below in Table 1.

Table 1. Demographics of the Respondents.

\begin{tabular}{ccc}
\hline Demographics Variable & Category & Percentage \\
\hline \multirow{2}{*}{ Gender } & Male & $70.4 \%$ \\
& Female & $29.6 \%$ \\
\hline \multirow{2}{*}{ Age } & Younger than 30 & $52.0 \%$ \\
& $30-39$ & $38.8 \%$ \\
& $40-49$ & $9.2 \%$ \\
\hline \multirow{2}{*}{ Education Degree } & Below junior college & $4.1 \%$ \\
& College & $25.5 \%$ \\
& University & $39.8 \%$ \\
& Master & $7.1 \%$ \\
& MBA/EMBA & $13.3 \%$ \\
& Doctor & $8.2 \%$ \\
& Others & $2.0 \%$ \\
\hline \multirow{2}{*}{ Working Years } & Below 5 years & $34.7 \%$ \\
& $5-9$ years & $42.9 \%$ \\
& $10-14$ years & $9.2 \%$ \\
& $15-19$ years & $9.2 \%$ \\
& 20-29 years & $4.0 \%$ \\
\hline
\end{tabular}

\subsection{Reliability and Validity}

Table 2 shows consistency for each measurement item under the same theoretical dimension in the survey question. The load of measurement factors of all variables is larger than 0.5 , which satisfies the requirements of convergent validity.

Table 2. Composite Reliability (CR), Average Variance Extracted (AVE), and Loading.

\begin{tabular}{ccc}
\hline Concept & Measurement Item & Loading \\
\hline AWS adoption & AA1 & 0.928 \\
$\mathrm{CR}=0.896 ;$ AVE $=0.745$ & AA2 & 0.936 \\
Cost & AA3 & 0.706 \\
\hline CR $=0.953 ;$ AVE $=0.843$ & CO1 & 0.873 \\
& CO2 & 0.930 \\
Cerceived relative advantage & CO3 & 0.950 \\
CR $=0.932 ;$ AVE $=0.773$ & RA1 & 0.903 \\
& RA2 & 0.831 \\
& RA3 & 0.884 \\
Operation performance & RA4 & 0.898 \\
CR $=0.903 ;$ AVE $=0.652$ & OP1 & 0.793 \\
& OP2 & 0.853 \\
& OP3 & 0.907 \\
Technological turbulence & OP4 & 0.710 \\
CR $=0.927 ;$ AVE $=0.809$ & OP5 & 0.761 \\
\hline
\end{tabular}


Table 2. Cont.

\begin{tabular}{ccc}
\hline Concept & Measurement Item & Loading \\
\hline & BPI1 & 0.883 \\
Business partner influence & BPI2 & 0.943 \\
CR $=0.953 ;$ AVE $=0.835$ & BPI3 & 0.938 \\
& BPI 4 & 0.888 \\
\hline Firm scope & FS1 & 0.750 \\
CR $=0.775 ;$ AVE $=0.533$ & FS2 & 0.768 \\
\hline
\end{tabular}

Table 3 shows that the factors with the highest mean values are the influence of partners, cost of AWS, operation performance, perceived relative advantage of AWS, and technical turbulence. Technical turbulence and perceived relative advantage are the same value, which indicates that firms focus on the benefits brought by the introduction of AWS. The mean value of AWS cost is higher than three, which indicates that enterprises also focus on the cost of AWS. High costs discourage an enterprise from using green technology. A mean value of operation performance below three indicates that most firms pay attention to the production efficiency of the equipment. AWS improves the stock structure and makes the storage space reasonable. AWS reduces the cost of transportation and storage.

Table 3. Mean Value and Variance.

\begin{tabular}{ccc}
\hline Constructs & Mean Value & Variance \\
\hline BPI & 2.6700 & 0.9080 \\
CO & 3.2500 & 1.1390 \\
OP & 3.4653 & 0.7020 \\
IS & 2.8980 & 1.8550 \\
TT & 3.3400 & 0.9400 \\
RA & 3.3400 & 0.8420 \\
\hline
\end{tabular}

Table 4 indicates that the average variance extracted (AVE) square root of each variable is larger than the correlation coefficient of other variables, which indicates good discriminant validity. The correlation coefficient among each variable is lower than 0.5 , and thus each variable in the survey questionnaire is mutually independent. This finding indicates that the measurement items of variables are not mutually influenced, and the respondents' attitude toward the item can be effectively measured.

Table 4. Average Variation Amount Extraction Square Root, and Correlation Coefficient.

\begin{tabular}{ccccccc}
\hline & BPI & CO & OP & IS & TT & RA \\
\hline BPI & 0.9136 & & & & & \\
CO & -0.2698 & 0.9181 & & & & \\
OP & 0.0293 & 0.0527 & 0.8076 & & & \\
IS & -0.1450 & 0.0219 & 0.2883 & 1.0000 & & \\
TT & 0.4579 & -0.0023 & 0.3111 & 0.1376 & 0.8996 & 0.8794 \\
RA & 0.4080 & 0.0092 & 0.1366 & -0.1735 & 0.1733 & \\
\hline
\end{tabular}

This statistical analysis shows that all current variables have high reliability and validity, therefore implying the validity of the model for the influences of TOE on AWS. Therefore, the information collected through the survey questionnaires can be considered to have high quality, and the related questions can be measured precisely.

\subsection{Structural Model Analysis and Hypotheses Test}

Figure 2 displays the results of path analysis and the explanatory power of the model ( $\mathrm{R}^{2}$ refers to the explanatory variable). Table 5 presents the results of the hypothesis testing. 


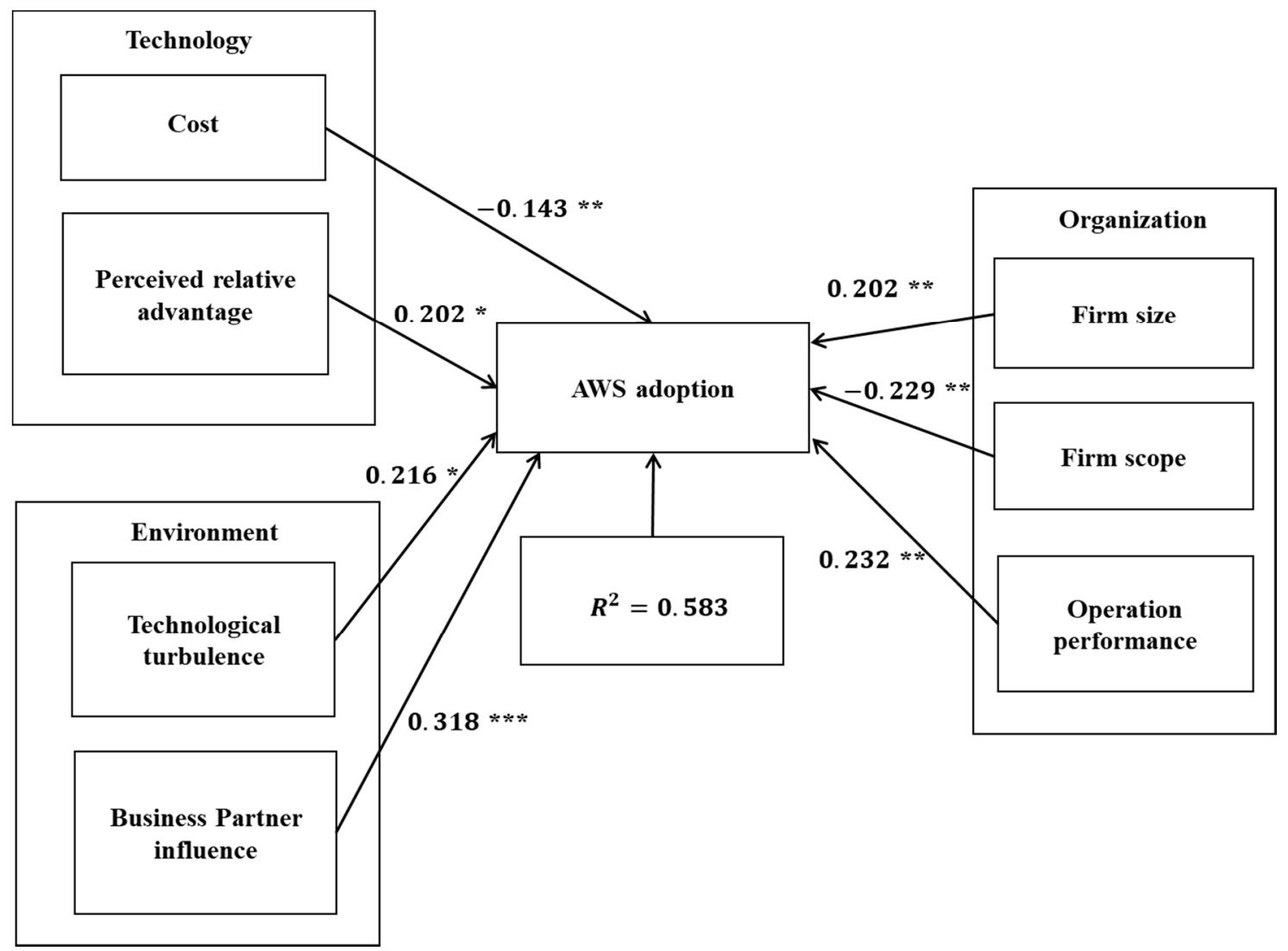

Figure 2. Results of Structural Model Testing. Notes: ${ }^{* *} p<0.001 ;{ }^{* *} p<0.01{ }^{*} p<0.05$.

Table 5. Summary of Tests of Model Paths and Comparison of Path Coefficients.

\begin{tabular}{|c|c|c|c|c|}
\hline Hypothesis & $\beta$ Value & $t$ Value & $p$ Value & Support? \\
\hline CO-AA & -0.143 & $2.060^{* *}$ & 0.004 & Yes \\
\hline $\mathrm{RA}-\mathrm{AA}$ & 0.202 & $1.991 *$ & 0.030 & Yes \\
\hline FS-AA & 0.202 & $2.785^{* *}$ & 0.007 & Yes \\
\hline IT-AA & -0.229 & $2.834^{* *}$ & 0.008 & Yes \\
\hline $\mathrm{OP}-\mathrm{AA}$ & 0.232 & $2.490^{* *}$ & 0.002 & Yes \\
\hline BPI-AA & 0.318 & $4.086^{* * *}$ & 0.000 & Yes \\
\hline TT-AA & 0.216 & $1.982 *$ & 0.021 & Yes \\
\hline
\end{tabular}

The analysis results show that the perceived relative advantage of AWS has a significant positive influence on the use of AWS ( $\beta=0.202, t=1.991$, and $p<0.05$ ). Therefore, Hypothesis 1 is supported. The higher the perceived relative advantage of AWS, the more inclined the enterprises are to adopt and utilize AWS. Firms also consider the benefit brought by the AWS application when using this technology. The cost of AWS has a significant negative influence $(\beta=-0.143, t=2.060$, and $p<0.05)$ on adoption of AWS. Therefore, Hypothesis 2 is established. This finding implies that the higher the cost of AWS, the less the enterprises will use this technology. The confirmed Hypotheses 1 and 2 both refer to the technical influences on AWS usage.

Firm size has remarkable positive influences $(\beta=0.202, t=2.785$, and $p<0.05)$ on the firms AWS usage. Therefore, Hypothesis 3 is established, which indicates that the larger the firm size, the more inclined the enterprises are to adopt and utilize AWS. Firm scope $(\beta=-0.229, t=2.834$, and $p<0.05)$ has significant reverse influences on AWS adoption. Operation performance $(\beta=0.232, t=2.490$, and $p<0.05$ ) has remarkable positive influences on the enterprise adoption of AWS systems, which 
indicates that Hypotheses 4 and 5 are supported. This finding shows that the larger the firm scope, the lower the possibility that the firms will use AWS. This may be because the high cost of introducing automated warehousing would force the enterprise to make changes in its business strategy. Therefore, a larger firm may be more cautious about using an automated warehousing system than a firm with a smaller scope would be. However, this finding also indicates that the increase in benefits brought by AWS introduction is appealing. Thus, firms become willing to use AWS.

The turbulence of warehouse technology has remarkable positive influence $(\beta=0.216, t=1.982$, and $p<0.05$ ) on the usage of AWS in firms. Therefore, Hypothesis 6 is established. The opportunity brought to firms by the turbulence of warehouse technology can motivate AWS usage. The influence of partners has $(\beta=0.318, t=4.086$, and $p<0.05)$ also had a remarkable positive effect on AWS usage, indicating that firms are highly likely to consider suggestions from business partners and customers.

\section{Discussion}

AWS is an important evolution of warehouse technology. The primary goals of AWS are cost effectiveness and space efficiency. This study finds that cost and perceived relative advantages of AWS using the technology perspective in the TOE framework markedly influence firms' adoption of green technology. The proposed model is empirically evaluated based on a sample of 98 Chinese firms. From the organizational perspective, firm size, firm scope, and operation performance have a remarkable influence on firms' AWS adoption. Likewise, turbulence in warehouse technology and the influence of partners both considerably influence the adoption of AWS. However, not all of these influences are positive. The AWS cost and firm scope have adverse influences on AWS usage.

Moreover, the cost and perceived relative advantage of AWS significantly influence the adoption of AWS. The enterprise evaluates the cost of AWS by focusing on the improvements brought by new technology to a firm. If the selling price of a new technology is high and exceeds the international scope that firms can afford, then this technology is perceived as inappropriate despite its advantages. Typically, firms consider cost saving when deciding whether to continue using their primary technology or introduce new technology. The lower the cost of AWS, the more willing the firms become to use AWS.

This study analyzes the factors that influence green technology adoption in the logistics industry. Our results indicate significant predictors, including cost and perceived relative advantage in the technology context, firm size, operation performance in the organizational context, and business partner influence in the environmental context. Cost in the technological context and firm scope in the organizational context negatively influence the adoption of green technology in the logistics industry.

\section{Conclusions}

This study contributes to the enhancement of AWS adoption measurement and provides guidance for firms considering adopting AWS as a guideline for sustainability value creation [1]. This empirical research will help firms decide whether to adopt AWS. By referring to the influencing factors of green technology adoption, firms can avoid the challenges brought by this technology due to insufficient consideration. This contribution can be further advanced by considering the theoretical and methodological implications of the results. Thus, this study provides direct empirical evidence to managers in the logistics industry. Small firms neglect to introduce new technology because they have no faith in the promise of improvement. The scope of a firm also influences the acceptance of new technology. Management might adopt more new technology when firms have several branches. Firms and managers should care for environmental sustainability issues once they accumulate an adequate level of innovation assets through patenting activities [35].

This study retains several limitations. First, our empirical results show that cost is an important factor. The variation in adoption based on firm size requires further investigation. The adoption level may vary widely depending on firm size. Second, the determinants of firms are associated with the number of years of using warehouse systems. However, the results cannot factor in the same experience for firms without warehouse systems. Third, the main limitation corresponds to the 
number of managers in each firm. There are several future research directions. First, research can focus on small and medium enterprises that face significant challenges in adopting AWS. Second, other potential influencing factors could also be investigated, such as the attitude of top management toward green technology adoption in the logistics industry. Third, our research can be extended into various contexts of supply chain management such as corporate social responsibility [36], closed-loop supply chains [37,38], and manufacturer encroachment [39].

Author Contributions: Conceptualization by H.S., V.S. and C.Y.; Data curation by J.H.; Funding acquisition by C.Y.; Methodology by J.H.; Supervision by V.S.; Writing — original draft by J.H.; Writing—review and editing by H.S., V.S. and C.Y. All authors have read and agreed to the published version of the manuscript.

Funding: This work was supported by the National Natural Science Foundation of China (No. 71771072) and Foundation of Zhejiang Educational Committee (Y201330222).

Acknowledgments: The authors would like to thank the editors and anonymous reviewers for their encouraging comments and insightful suggestions, which substantially improved the quality of the paper.

Conflicts of Interest: The authors declare no conflict of interest.

\section{Appendix A List of the Items by Construct}

\section{Perceived relative advantage}

RA1: We believe that AWS allows us to accomplish specific tasks more quickly.

RA2: We believe that AWS allows us to enhance our productivity.

RA3: We believe that AWS allows us to save time in searching for resources.

RA4: We believe that AWS allows us to improve our job performance.

\section{Cost}

CO1: We believe that the cost of AWS is high for our company.

$\mathrm{CO} 2$ : We believe that the amount of money and time of training for AWS applications is high for our company.

CO3: We believe that the maintenance and support fees for AWS applications are high for our company.

Operation performance

OP1: Our firm can quickly modify products to meet our major customer's requirements.

OP2: Our firm can quickly introduce new products into the market.

OP3: Our firm can respond to changes in market demand.

OP4: Our firm has an outstanding on-time delivery record for our major customers.

OP5: Our firm provides a high level of customer service to our major customers.

\section{Technological turbulence}

TT1: It is easy for our customers to switch to another firm for similar products without much difficulty.

TT2: The rivalry among firms in the industry my firm is operating in is very intense.

TT3: There are many products in the market which are different from ours but perform the same functions.

\section{Business partner influence}

BPI1: Important business partners have made requests to us to use AWS.

BPI2: Major business partners have recommended that we use AWS.

BPI3: Important business partners have recommended that we use AWS.

BPI4: Major business partners have requested that we use AWS. 
Firm scope

FS1: Multi-established (Y/N)

FS2: Establishments outside of country $(\mathrm{Y} / \mathrm{N})$

Firm size

SI1: Assets

SI2: Number of employees

SI3: Annual sales

AWS adoption

AA1: I would like to adopt AWS in the next (n) months.

AA2: I would like to adopt AWS in the next (n) months.

AA3: I would like to adopt AWS in the next (n) months.

\section{References}

1. Hristov, I.; Chirico, A.; Appolloni, A. Sustainability Value Creation, Survival, and Growth of the Company: A Critical Perspective in the Sustainability Balanced Scorecard (SBSC). Sustainability 2019, 11, 2119. [CrossRef]

2. Kovacs, G.; Kot, S. New logistics and production trends as the effect of global economy changes. Pol. J. Manag. Stud. 2016, 14, 115-126. [CrossRef]

3. Afonasova, M.A.; Panfilova, E.E.; Galichkina, M.A.; Ślusarczyk, B. Digitalization in economy and innovation: The effect on social and economic processes. Pol. J. Manag. Stud. 2019, 19, 22-32.

4. Fujii, H.; Managi, S. Decomposition analysis of sustainable green technology inventions in China. Technol. Forecast. Soc. Chang. 2019, 139, 10-16. [CrossRef]

5. Chih-Cheng, C.; Chen, C.-W.; Tung, Y.-C. Exploring the Consumer Behavior of Intention to Purchase Green Products in Belt and Road Countries: An Empirical Analysis. Sustainability 2018, 10, 854. [CrossRef]

6. De Koster, R.; Le-Duc, T.; Roodbergen, K.J. Design and control of warehouse order picking: A literature review. Eur. J. Oper. Res. 2007, 182, 481-501. [CrossRef]

7. Lan, S.; Tseng, M.-L.; Yang, C.; Huisingh, D. Trends in sustainable logistics in major cities in China. Sci. Total. Environ. 2020, 712, 136381. [CrossRef]

8. Wang, Y.S.; Li, H.T.; Li, C.R.; Zhang, D.Z. Factors affecting hotels' adoption of mobile reservation systems: A TOE framework. Tour. Manag. 2016, 53, 163-172. [CrossRef]

9. Martelo-Landroguez, S.; Albort-Morant, G.; Leal-Rodriguez, A.L.; Ribeiro-Soriano, B. The Effect of Absorptive Capacity on Green Customer Capital under an Organizational Unlearning Context. Sustainability 2018, 10, 265. [CrossRef]

10. Randhawa, S.U.; Shroff, R. Simulation-based design evaluation of unit load automated storage/retrieval systems. Comput. Ind. Eng. 1995, 28, 71-79. [CrossRef]

11. Vasili, M.; Vasili, M.; Raminfar, R. A closed form model for travel time of split-platform automated storage and retrieval system equipped with two input/output stations. In Proceedings of the 9th International Conference on Modeling, Optimization \& Simulation, Bordeaux, France, 6-8 June 2012.

12. Ashayeri, J.; Heuts, R.M.J.; Beekhof, M.; Wilhelm, M.R. On the Determination of Class-Based Storage Assignments in an AS/RS Having Two I/O Locations; Progress in Material Handling Research; Material Handling Institute: Charlotte, NC, USA, 2001; pp. 27-41.

13. Lerher, T. Design and evaluation of the class-based multi-aisle AS/RS. Int. J. Simul. Model. 2006, 5, 25-36. [CrossRef]

14. Yu, Y.; De Koster, R. Sequencing heuristics for storing and retrieving unit loads in 3D compact automated warehousing systems. IIE Trans. 2012, 44, 69-87. [CrossRef]

15. Ha, Y.; Chae, J. Free balancing for a shuttle-based storage and retrieval system. Simul. Model. Pr. Theory 2018, 82, 12-31. [CrossRef]

16. Bozer, Y.A.; White, J.A. Travel-Time Models for Automated Storage/Retrieval Systems. IIE Trans. 1984, 16, 329-338. [CrossRef] 
17. De Koster, R.; Le-Duc, T.; Yugang, Y. Optimal storage rack design for a 3-dimensional compact AS/RS. Int. J. Prod. Res. 2008, 46, 1495-1514. [CrossRef]

18. Ekren, B.; Sari, Z.; Lerher, T. Warehouse Design under Class-Based Storage Policy of Shuttle-Based Storage and Retrieval System. IFAC-PapersOnLine 2015, 48, 1152-1154. [CrossRef]

19. Oliveira, T.; Martins, R.; Sarker, S.; Thomas, M.; Popovič, A. Understanding SaaS adoption: The moderating impact of the environment context. Int. J. Inf. Manag. 2019, 49, 1-12. [CrossRef]

20. Xia, D.; Zhang, M.; Yu, Q.; Tu, Y. Developing a framework to identify barriers of Green technology adoption for enterprises. Resour. Conserv. Recycl. 2019, 143, 99-110. [CrossRef]

21. Zhu, K.; Kraemer, K.L. Post-Adoption Variations in Usage and Value of E-Business by Organizations: Cross-Country Evidence from the Retail Industry. Inf. Syst. Res. 2005, 16, 61-84. [CrossRef]

22. Jean, R.-J.B.; Sinkovics, R.R.; Kim, D. The impact of technological, organizational and environmental characteristics on electronic collaboration and relationship performance in international customer-supplier relationships. Inf. Manag. 2014, 51, 854-864. [CrossRef]

23. Aboelmaged, M. Predicting e-readiness at firm-level: An analysis of technological, organizational and environmental (TOE) effects on e-maintenance readiness in manufacturing firms. Int. J. Inf. Manag. 2014, 34, 639-651. [CrossRef]

24. Teo, T.S.; Lin, S.; Lai, K.-H. Adopters and non-adopters of e-procurement in Singapore: An empirical study. Omega 2009, 37, 972-987. [CrossRef]

25. Frambach, R.T.; Schillewaert, N. Organizational innovation adoption: A multi-level framework of determinants and opportunities for future research. J. Bus. Res. 2002, 55, 163-176. [CrossRef]

26. Thong, J.Y.L.; Yap, C. CEO characteristics, organizational characteristics and information technology adoption in small businesses. Omega 1995, 23, 429-442. [CrossRef]

27. Yoon, C.; Lim, D.; Park, C. Factors affecting adoption of smart farms: The case of Korea. Comput. Hum. Behav. 2020, 108, 106309. [CrossRef]

28. Chatterjee, S.; Kar, A.K. Why do small and medium enterprises use social media marketing and what is the impact: Empirical insights from India. Int. J. Inf. Manag. 2020, 53, 102103. [CrossRef]

29. Cruz-Jesus, F.; Pinheiro, A.; Oliveira, T. Understanding CRM adoption stages: Empirical analysis building on the TOE framework. Comput. Ind. 2019, 109, 1-13. [CrossRef]

30. Liu, Q.; Geertshuis, S.; Grainger, R. Understanding academics' adoption of learning technologies: A systematic review. Comput. Educ. 2020, 151, 103857. [CrossRef]

31. Premkumar, G.; Roberts, M. Adoption of new information technologies in rural small businesses. Omega 1999, 27, 467-484. [CrossRef]

32. Ingrid, M.; Patrick, D.P. An Extended Decomposed Theory of Planned Behaviour to Predict the Usage Intention of the Electric Car: A Multi-Group Comparison. Sustainability 2015, 7, 6212-6245.

33. Park, E.; Lim, J.; Cho, Y. Understanding the Emergence and Social Acceptance of Electric Vehicles as Next-Generation Models for the Automobile Industry. Sustainability 2018, 10, 662. [CrossRef]

34. Rezaee, Z. Supply Chain Management and Business Sustainability Synergy: A Theoretical and Integrated Perspective. Sustainability 2018, 10, 275. [CrossRef]

35. Lee, J.; Kim, S.-J. Curvilinear Relationship between Corporate Innovation and Environmental Sustainability. Sustainability 2017, 9, 1267. [CrossRef]

36. Bian, J.; Liao, Y.; Wang, Y.-Y.; Tao, F. Analysis of firm CSR strategies. Eur. J. Oper. Res. 2020. [CrossRef]

37. Liu, Z.; Li, K.W.; Li, B.-Y.; Huang, J.; Tang, J. Impact of product-design strategies on the operations of a closed-loop supply chain. Transp. Res. Part E Logist. Transp. Rev. 2019, 124, 75-91. [CrossRef]

38. Zheng, X.-X.; Liu, Z.; Li, K.W.; Huang, J.; Chen, J. Cooperative game approaches to coordinating a three-echelon closed-loop supply chain with fairness concerns. Int. J. Prod. Econ. 2019, 212, 92-110. [CrossRef]

39. Li, J.; Yi, L.; Shi, V.; Chen, X. Supplier encroachment strategy in the presence of retail strategic inventory: Centralization or decentralization? Omega 2020, 102213. [CrossRef]

(C) 2020 by the authors. Licensee MDPI, Basel, Switzerland. This article is an open access article distributed under the terms and conditions of the Creative Commons Attribution (CC BY) license (http://creativecommons.org/licenses/by/4.0/). 